\title{
CYTOGENETIC SURVEY OF PRIMARY AMENORRHEA
}

\author{
Mei-Show Ko \\ Department of Obstetric and Gynecology, Tohoku University \\ School of Medicine, Sendai 980, Japan
}

\begin{abstract}
Summary Fifty-nine cases with clinical signs of primary amenorrhea are investigated. Classification of primary amenorrhea was made based on chromosome analysis, endocrine studies and clinical findings. The incidence of primary amenorrhea patients is $0.3 \%$ in present study. Out of 59 cases with primary amenorrhea, 22 had chromosome abnormalities being represented by 12 cases with $45, X / 46, X X, 3$ cases with $46, X, i(X q)$, 2 cases with $45, X / 46, X, r(X)$, one each with $46, X X / 46, X, i(X q)$ and $45, X /$ $46, X, \mathrm{i}(\mathrm{Xq})$, and 3 with $46, \mathrm{XY}$. Thirteen are due to vaginal agenesis, 17 to ovarian origin, 4 to pituitary origin, and one each to adrenogenital syndrome, diabetes mellitus and hyperthyroidism, respectively. The stature and clinical picture of the patients is correlated with the absence or deletion of one $\mathrm{X}$ chromosome. When 13 patients with vaginal agenesis are excluded, 22 out of 46 primary amenorrhea patients showed abnormalities of chromosome, giving the incidence of $47.8 \%$. This is higher than the incidences reported in some previous papers.
\end{abstract}

\section{INTRODUCTION}

Considerable cytogenetic studies on primary amenorrhea have been available in the recent iterature (Evans, 1971; Chrysostomidou, 1971; Black and Govan, 1972; Kallio, 1973; Sarto, 1974; Baron and Warenik-Szymankiewics, 1975; Bhasin and Fuhrmann, 1976). These studies have noted certain chromosomal abnormalities as possible causes of primary amenorrhea in addition to functional imbalance of endocrine system. Our knowledge has remained rather insufficiently. Over-all pictures of these clinical conditions being apparently incomplete. Primary amenorrhea has been undertaken during recent 5 years in our laboratory. In addition to clinical examinations, we have carried out radiological, intelligent (I.Q.), dermatographic, hormonal, and cytogenetic investigations on these patients. In this paper is presented a cytogenetic findings in 59 patients with this defect, in an aim to correlate, if possible, with the clinical features.

Received October 20, 1981

Present address: Department of Obstetrics and Gynecology, Miyazaki Provincial Nobeoka Hospital, Nobeoka 882, Japan. 


\section{MATERIALS AND METHODS}

The subjects of this study consisted of 59 patients who had never menstruated, and were presented at the special clinic "Ovarian Dysgenesis" in our obstetrical and gynecological department, during from January 1, 1974 to August 30, 1978.

Primary amenorrhea is difficult to define theoretically, but generally, for practical purpose, it is defined as a condition in which a woman at 18 years of age or more has never menstruation.

The specific case history was obtained, a complete physical examination was done, and measurements of thyroid, adrenal and pituitary function were carried out whenever possible. Thyroid function was measured by B.M.R. and T.S.H., and adrenocortical activity by 17-ketosteroids and 17-hydroxycorticosteroids in $24 \mathrm{hr}$ urine. Pituitary function was checked by LH-RH test. Bone age was assessed by wrist joint. Buccal smears were examined for sex chromatin, after being fixed in the $1: 1$ solution of ether and $95 \%$ alcohol, and stained with $1 \%$ cresylecht-violet. Cytogenetic analysis of chromosome was carried out on metaphases obtained from short-term leucocyte cultures by a modification of Moorhead et al. (1960). Slides were made by the routine air-drying method and stained in buffered Giemsa solution.

\section{RESULTS}

The details on the incidence of primary amenorrhea in random series were not available. The present series was collected in the period ranging from January 1 , 1974 to August 30, 1978. We had in the outpatient clinic 20,183 new patients of which the total number of primary amenorrhea patients was 59 , thus giving the incidence of $0.3 \%$.

Of 59 patients with primary amenorrhea cytogenetically studied, 22 were found to possess various kinds of chromosome abnormalities which were represented by 12 patients with $45, X / 46, X X, 3$ with $46, X, i(X q), 2$ with $45, X / 46, X, r(X)$, one each with $46, X X / 46, X, i(X q)$ and $45, X / 46, X, i(X q)$, and 3 with $46, X Y$. The remaining 37 patients were found to have an apparently normal female karyotype, of which 13 cases were vaginal agenesis.

Classification of primary amenorrhea was attempted according to the endocrine, chromosomal, and clinical findings. In 17 cases the etiology for the amenorrhea was presumed to be ovarian origin, as determined by elevated gonadotropin excretion and/or streak gonads. In 4 cases, the amenorrhea was thought to be due to pituitary origin, as determined by low pituitary gonadotropin excretion and/or under developed ovaries. There were 13 cases in which the amenorrhea was due to vaginal agenesis, 6 being Mayer-Rokitansky-Küster syndrome, 4 characteristic of absence of the vagina, one with vaginal diaphragm and 2 with vaginal atresia. In 3 cases, the amenorrhea seemed to be attributable to other causes involving adrenogenital syn- 
drome, diabetes mellitus and hyperthyroidism. The results of present study was presented in Table 1.

The frequencies of sex chromatin in normal females reported by former authors were presented in Table 2. The results of present study was shown as $28.6 \pm 5.3 \%$

Table 1. Etiology of primary amenorrhea in the present series.

\begin{tabular}{ccc}
\multicolumn{1}{c}{ Etiology } & Cases & $\%$ \\
\hline I. $\begin{array}{l}\text { Chromosome abnomality } \\
\text { Turner's syndrome } \\
\text { Testicular feminization syndrome }\end{array}$ & 22 & 37.3 \\
\hline II. & $(19)$ & $(32.2)$ \\
\hline Pituitary origin & $(3)$ & $(5.1)$ \\
\hline OII. Ovarian origin & 4 & 6.8 \\
Ovarian dysfunction & 17 & 28.8 \\
Polycystic ovary & $(16)$ & $(27.1)$ \\
\hline IV. Vaginal agenesis & $(1)$ & $(1.7)$ \\
Mayer-Rokitansky-Küster syndrome & 13 & 22.0 \\
Absence of the vagina & $(6)$ & $(10.1)$ \\
Vaginal diaphragm & $(4)$ & $(6.8)$ \\
Vaginal atresia & $(1)$ & $(3.4)$ \\
\hline V. Symptomaic amenorrhea & $(2)$ & 5.1 \\
Adrenogenital syndrome & 3 & $(1.7)$ \\
Diabetes mellitus & $(1)$ & $(1.7)$ \\
Hyperthyroidism & $(1)$ & $(1.7)$ \\
\hline
\end{tabular}

Table 2. Frequencies of sex chromatin in normal females with $46, \mathrm{XX}$ in reported cases.

\begin{tabular}{lcc}
\hline \multicolumn{1}{c}{ Author } & Frequency \\
\hline Present study & & $19-37 \%$ \\
& & $(28.6 \pm 5.3)$ \\
Moore \& Barr & 1955 & $40-60 \%$ \\
De La Chapelle & 1962 & $31 \%$ \\
Knut Bjøro & 1965 & $16-52 \%$ \\
& & Mean $38 \%$ \\
Barakat \& Jones & 1970 & $20-50 \%$ \\
Lucas & 1971 & $10-30 \%$ \\
Kallio & 1973 & $27.1 \%$ \\
Nankin \& Louidice & 1974 & $16-34 \%$ \\
& & Mean $25 \%$ \\
\hline
\end{tabular}

Vol. 27, No. 1, 1982 
on an average. The frequencies of sex chromatin in patients with primary amenorrhea were given in Table 3. The patient with testicular feminization $(46, X Y)$ was sex chromatin negative, being identical with the previous reports. The sex chromatin frequency in patients with $45, \mathrm{X} / 46, \mathrm{XX}$ was 0 to $17 \%$, being considerably lower than in the reported cases. The sex chromatin frequency in those with $45, \mathrm{X} /$ $46, \mathrm{X}, \mathrm{r}(\mathrm{X})$ was 5 to $18 \%$, showing a considerably higher frequency than in the reported cases. The frequency in $46, \mathrm{X}, \mathrm{i}(\mathrm{Xq})$ patients was 7.3 to $28.7 \%$, being rather lower than in the previous cases.

The chromosome constitutions represented by $45, \mathrm{X} / 46, \mathrm{XX}, 45, \mathrm{X} / 46, \mathrm{X}, \mathrm{r}(\mathrm{X})$ and $46, X, i(X q)$ show uniformly the absence of one $X$ chromosome from one cell line, or the absence of the short arm of one $X$ chromosome. The patients with these conditions are to be included in the same group, short stature being generally characteristic to this group. The stature observed in 50 normal women was shown as $156.7 \pm 4.8 \mathrm{~cm}$. The stature of the $46, X X$ patients with primary amenorrhea was found as $150.5 \pm 9.7 \mathrm{~cm}$, that of the $45, X / 46, X X$ patient was $137.3 \pm 11.1 \mathrm{~cm}$, that of $45, X / 46, X, r(X)$ patient was $131.8 \pm 1.4 \mathrm{~cm}$, that of $45, X / 46, X, i(X q)$ patient was $128.8 \mathrm{~cm}$, and that of $46, \mathrm{X}, \mathrm{i}(\mathrm{Xq})$ patient was $127.9 \pm 6.4 \mathrm{~cm}$. From the above data

Table 3. Frequencies of sex chromatin in patients with primary amenorrhea in the present and former studies.

\begin{tabular}{|c|c|c|}
\hline Karyotype & Present study & $\begin{array}{l}\text { Literature } \\
\text { Min-Max }\end{array}$ \\
\hline Normal female with $46, X X$ & $\begin{array}{c}19-37 \% \\
(28.6 \pm 5.3)\end{array}$ & $\begin{array}{c}16-34 \% \\
\text { Mean } 25 \%\end{array}$ \\
\hline \multicolumn{3}{|l|}{ Primary amenorrhea with $46, \mathrm{XX}$} \\
\hline Pituitary origin & $\begin{array}{c}18-27 \% \\
(24.5 \pm 3.8)\end{array}$ & \\
\hline Ovarian origin & $\begin{array}{c}13-32 \% \\
(24.5 \pm 5.9)\end{array}$ & \\
\hline Symptomatic amenorrhea & $\begin{array}{c}26-31 \% \\
(28.5 \pm 2.5)\end{array}$ & \\
\hline Testicular feminization syndrome $46, \mathrm{XY}$ & $0 \%$ & $0 \%$ \\
\hline $46, \mathrm{XX} / 46, \mathrm{X}, \mathrm{i}(\mathrm{Xq})$ & $23 \%$ & $33 \%$ \\
\hline $45, \mathrm{X} / 46, \mathrm{XX}$ & $\begin{array}{c}0-17 \% \\
(6.6 \pm 5.3)\end{array}$ & $0-32 \%$ \\
\hline $45, X / 46, X, r(X)$ & $\begin{array}{c}5-18 \% \\
(11.5 \pm 6.5)\end{array}$ & $0-12 \%$ \\
\hline $45, \mathrm{X} / 46, \mathrm{X}, \mathrm{i}(\mathrm{Xq})$ & $0 \%$ & $9-48 \%$ \\
\hline $46, \mathrm{X}, \mathrm{i}(\mathrm{Xq})$ & $\begin{array}{l}7.3-28.7 \% \\
(18 \pm 10.7)\end{array}$ & $20-46 \%$ \\
\hline
\end{tabular}




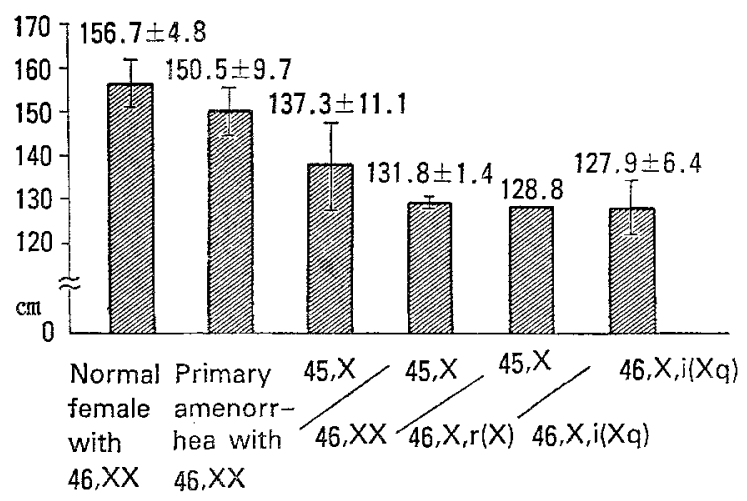

Fig. 1. Relation of karyotype to stature.

Table 4. Relation of karyotype to clinical pictures observed in primary amenorrhea patients.

\begin{tabular}{|c|c|c|c|c|c|c|}
\hline & $\begin{array}{c}\text { Primary } \\
\text { amenorrhea } \\
\text { with } 46, X X\end{array}$ & $45, \mathrm{X} / 46, \mathrm{XX}$ & $46, \mathrm{X}, \mathrm{i}(\mathrm{Xq})$ & $\begin{array}{c}45, X / \\
46, X, r(X)\end{array}$ & $\begin{array}{c}45, X / \\
46, X, \mathrm{X}(\mathrm{Xq})\end{array}$ & $\begin{array}{c}46, X X / \\
46, X, i(X q)\end{array}$ \\
\hline Uterine hypoplasia & $9 / 23 \quad 39 \%$ & $8 / 11 \quad 73 \%$ & $3 / 3 \quad 100 \%$ & $2 / 2$ & $1 / 1$ & $0 / 1$ \\
\hline Breast hypoplasia & $11 / 23 \quad 48 \%$ & $9 / 1182 \%$ & $3 / 3 \quad 100 \%$ & $2 / 2$ & $0 / 1$ & $1 / 1$ \\
\hline Absence of axillary hair & $8 / 23 \quad 35 \%$ & $8 / 11 \quad 73 \%$ & $3 / 3 \quad 100 \%$ & $2 / 2$ & $1 / 1$ & $0 / 1$ \\
\hline Absence of pubic hair & $2 / 23 \quad 9 \%$ & $7 / 11 \quad 64 \%$ & $3 / 3 \quad 100 \%$ & $2 / 2$ & $1 / 1$ & $0 / 1$ \\
\hline Cubitus valgus & $5 / 23 \quad 22 \%$ & $8 / 11 \quad 73 \%$ & $3 / 3 \quad 100 \%$ & $2 / 2$ & $1 / 1$ & $1 / 1$ \\
\hline Pigmented nevi & $0 / 23 \quad 0 \%$ & $0 / 11 \quad 0 \%$ & $2 / 3 \quad 67 \%$ & $0 / 2$ & $0 / 1$ & $0 / 1$ \\
\hline
\end{tabular}

(Fig. 1), it is apparent that the stature of the primary amenorrhea patients is correlated with the absence or deletion of one X chromosome.

The relation of the karyotypes to clinical pictures were studied in the present series. The results were presented in Table 4. The occurrence of physical anomalies such as breast hypoplasia, uterine hypoplasia, absence of axillary hair, absence of pubic hair, and cubitus valgus were found to be correlated with the abnormality of one $\mathrm{X}$ chromosome. The unique symptom was the occurrence of pigmented nevi in the $46, \mathrm{X}, \mathrm{i}(\mathrm{Xq})$ patient. Such a clinical sign was not seen in other patients in agreement with Kallio's (1973) findings.

The frequencies of chromosome abnormalities reported by previous authors are presented in Table 5, in comparison with those by the present study. It was shown that the frequency of primary amenorrhea patients with the $46, \mathrm{XX}$ constitution was $73.6 \%$ in the previous studies. The frequency obtained in the present survey was $62.7 \%$ on an average. However, when 13 patients with vaginal agenesis were excluded, the frequency of the patients with normal chromosome constitution was $52.2 \%$. The frequency of primary amenorrhea patients with abnormal chromosome constitutions was found as $47.8 \%$. This seems to lead the conclusion that 
Table 5. Frequencies of chromosome abnormalities in primary amenorrhea patients.

\begin{tabular}{|c|c|c|c|c|c|c|c|}
\hline \multirow[b]{2}{*}{ Author } & & \multirow[b]{2}{*}{ Cases } & \multicolumn{5}{|c|}{ Chromosome constitution } \\
\hline & & & $46, X X$ & $46, X Y$ & $46, X, i(X q)$ & $45, X$ & $\begin{array}{c}46, X X / \\
46, X, i(X q)\end{array}$ \\
\hline Evans & 1971 & 50 & 38 & 2 & - & 5 & 一 \\
\hline Chrysostomidou & 1971 & 60 & 40 & - & - & 7 & - \\
\hline Black \& Govan & 1972 & 20 & 16 & 2 & - & 1 & - \\
\hline Kallio & 1973 & 100 & 80 & 6 & 1 & 9 & - \\
\hline Sarto & 1974 & 50 & 31 & 3 & 1 & 9 & - \\
\hline Baron & 1975 & 125 & 95 & 8 & 一. & 9 & - \\
\hline Bhasin & 1976 & 15 & 9 & 1 & - & 3 & - \\
\hline Total & & 420 & $\begin{array}{c}309 \\
(73.6 \%)\end{array}$ & $\begin{array}{c}22 \\
(5.2 \%)\end{array}$ & $\begin{array}{l}2 \\
(0.4 \%)\end{array}$ & $\begin{array}{c}43 \\
10.2 \%)\end{array}$ & - \\
\hline Present_study & & 59 & $\begin{array}{c}37 \\
(62.7 \%)\end{array}$ & $\begin{array}{c}3 \\
(5.1 \%)\end{array}$ & $\begin{array}{c}3 \\
(5.1 \%)\end{array}$ & - & $\begin{array}{c}1 \\
(1.7 \%)\end{array}$ \\
\hline \multirow[b]{2}{*}{ Author } & & \multirow[b]{2}{*}{ Cases } & \multicolumn{5}{|c|}{ Chromosome constitution } \\
\hline & & & $\begin{array}{l}45, X 1 \\
46, X X\end{array}$ & $\begin{array}{c}45, X / \\
46, X, r(X)\end{array}$ & $\begin{array}{c}45, X / \\
46, X, 1(X q)\end{array}$ & $\begin{array}{c}45, X / \\
46, X Y\end{array}$ & Others \\
\hline Evans & 1971 & 50 & 5 & - & - & 一 & - \\
\hline Chrysostomidou & 1971 & 60 & - & - & 9 & - & 4 \\
\hline Black \& Govan & 1972 & 20 & - & - & 一 & 1 & 一 \\
\hline Kallio & 1973 & 100 & 2 & - & 1 & - & 1 \\
\hline Sarto & 1974 & 50 & - & - & 1 & - & 5 \\
\hline Baron & 1975 & 125 & 4 & 1 & 1 & 2 & 5 \\
\hline Bhasin & 1976 & 15 & - & - & - & - & 2 \\
\hline Total & & 420 & $\begin{array}{c}11 \\
(2.6 \%)\end{array}$ & $\begin{array}{c}1 \\
(0.2 \%)\end{array}$ & $\begin{array}{c}12 \\
(2.9 \%)\end{array}$ & $\begin{array}{c}3 \\
(0.7 \%) \\
\end{array}$ & $\begin{array}{c}17 \\
(4.0 \%) \\
\end{array}$ \\
\hline Present study & & 59 & $\begin{array}{c}12 \\
(20.3 \%)\end{array}$ & $\begin{array}{c}2 \\
(3.4 \%)\end{array}$ & $\begin{array}{c}1 \\
(1.7 \%)\end{array}$ & - & - \\
\hline
\end{tabular}

patients with primary amenorrhea should be investigated with regard to the chromosome analysis, particularly in relation to the incidence.

\section{DISCUSSION}

There is a diversity of opinion about the age of the patients with primary amenorrhea in investigation. In the present study, menarche was calculated on 1,000 normal postpartal women. In $99.9 \%$ of the women had experienced menarche at 
18 years of age. Therefore, primary amenorrhea is to be defined as the condition in which a woman at 18 years of age or more has never menstruated. The definition of primary amenorrhea was shown by several authors as follows: 1) the age of 19 is eventually shown to have no more than a delayed menarche (Jacobs et al., 1961); 2) the failure of onset of bleeding in phenotypic women at 18 years of age or more (Philip et al., 1965); 3) the age of 18 may be taken as the borderline between the normal and the pathological (Kunt, 1965); 4) the 18th year is an age often advanced (Shearman, 1968); 5) menstruation falls to begin before the 18th of age (Kallio, 1973); and 6) the age of 18 years or older has never menstruation (Sarto, 1974).

Primary amenorrhea is a rare disease and the over-all picture of these clinical conditions is rather incomplete. Detailed data on the incidence of the primary amenorrhea in random series has not been available. In the present study, the incidence was shown as $0.3 \%$. This is lower than the incidences reported by Kurachi (1969) as $0.39 \%$ and by Kallio (1973) as $0.41 \%$.

Cytogenetic investigation was made on 59 patients who had never menstruation, and 22 of them were found to show chromosome abnormalities which were represented by 12 cases with $45, X / 46, X X, 3$ cases with $46, X, i(X q), 2$ cases with $45, X$ / $46, X, r(X), 3$ cases with $46, X Y$, and one each with $46, X X / 46, X, i(X q)$ and $45, X /$ $46, X, \mathrm{i}(\mathrm{Xq})$. If 13 patients with vaginal agenesis were excluded, 22 out of 46 primary amenorrhea patients showed chromosome abnormalities. The incidence was $47.8 \%$ being higher than those reported by previous authors presented in Table 5. In sum, there was high possibility that much mosaic Turner was included in the $46, \mathrm{XX}$ constitution which was diagnosed by previous authors. The frequency of $45, \mathrm{X} / 46, \mathrm{XX}$ constitution was $2.6 \%$ in the previous studies and $20.3 \%$ in the present survey. Mosaic Turner increased significantly in the present survey. On the other hand, $45, \mathrm{X}$ constitution was $10.2 \%$ in previous studies, in contrast, the present study had failed to demonstrate any one case. Outstanding high $45, \mathrm{X}$ constitution in previous studies was demonstrated that many mosaic Turner was included in the 45 , X constitution which was diagnosed in previous studies. This sums to lead the conclusion that under the view of cytogenetic field, if patient with vaginal agenesis are excluded, the frequency of primary amenorrhea patients with abnormal chromosome constitutions are about $50 \%$. To-date, 13 cases of primary amenorrhea in which autosomal aberrations were found have been referred to in the literature (Jascobs et al., 1961; Edwards, 1961; Hirschhorn, 1968; Ikeuchi et al., 1968; Kadotani et al., 1969; Sarto, 1974; Bhasin and Fuhrmann, 1976). In contrast, the present study had failed to demonstrate any one case showing autosomal aberrations. Their causal relationship to amenorrhea has remained unknown.

Acknowledgement My sincere gratitude is due to Prof. Masakuni Suzuki, Tohoku University, and Dr. Sajiro Makino, M.J.A. for invaluable criticism on the findings and readings through the manuscript.

This paper has been represented at the 24th Annual Meeting of the Japan Society of Human Genetics at Tokyo, Japan, November 3-5, 1979. 


\section{REFERENCES}

Barakat, B.Y., and Jones, H.W. 1970. Gynecologic and cytogenetic aspects of gonadal agenesis and dysgenesis. Obstet. Gynecol. 36: 368-372.

Baron, J. Von., und Warenik-Szymankiewics, A. 1975. Zytogenetische untersuchungen bei der primären amenorrhoe. Zbl. Gynack. 97: 649-655.

Bhasin, M.K., and Fuhrmann, W. 1976. Cytogenetic study in primary amenorrhea. Jpn. J. Human Genet. 20(4): 313-320.

Black, W.P., and Govan, A.D.T. 1972. Laparoscopy and gonadal biopsy for assessment of gonadal function in primary amenorrhea. $B r . M e d . J .1: 672-675$.

Chrysostomidou, O.M. 1971. Cytogenetic study of 60 cases of primary amenorrhea. Genetics V 157 XII Int-cong. Pediat. Austria.

De La Chapelle, A. 1962. Cytogenetical and clinical observation in female gonadal dysgenesis. Acta Endoer. Suppl. 65: $98-100$.

Evans, J.H. 1971. A review of 50 cases of primary amenorrhea. Aust. N. Zealand. J. Obstet. Gynaecol. 11: 7-8.

Edwards, J.H. 1961. Barr bodies. Lancet 1: 616-619.

Hirschhorn, K. 1965. Abnormalities of the acrocentric chromosomes. Proc. 11th Intern. Congr. Genet. The Hague, 1963, Pergsmon Press, Oxford. 1: 304

Ikeuchi, T., Fujimoto, S., and Makino, S. 1968. Notes on chromosome abnormalities found in some patients with primary amenorrhea. Proc. Ipn. Acad. 44: 711-716.

Jacobs, P.A., Harnden, D.G., Buckton, K.E., Courtbroun, W.M., King, M.J., MacBride, J.A., MacGregor, T.N., and Maclean, N. 1961. Cytogenetic studies in primary amenorrhea. Lancet 1: 1183-1188.

Kallio, H. 1973. Cytogenetic and clinical study on 100 cases of primary amenorrhea. Acta Obstet. Gynecol. Scandinavica, Supplement 24: 7-78.

Kadotani, T., Ohama, K., and Sato, N. 1969. A preliminary cytogenetic survey in primary amenorrhea. Jpn. J. Human Genet. $13: 278-284$.

Kunt Bjøro. 1965. Primary amenorrhea-A study with special reference to the morphology of the genital organs. Acta Obstet. ET. Gynecol. Scandinavica, Vol. XLIV, Supplement 4: 41-43.

Kurachi, K. 1969. Diagnosis and treatment of primary amenorrhea. Obstet. Gynecol. Therapy 18: $363-365$.

Lucas, M. Dewhurst, C.J., Hurley, R., Anderson, S., and Blunt, S. 1971. A search for triple X femeles in a fertile population. J. Obstet. Gynaec. Brit. Commonw. 78: 1087-1090.

Moorhead, P.S., Nowell, P.C., Mellman, W.J., Battips, D.M., and Hungerford, D.A. 1960. Chromosomes preparations of leukocytes cultured from human peripheral blood. Exp. Cell Res. 20: 613-616.

Moore, K.L., and Barr, M.L. 1955. Smears from the oral musoca in the detection of chromosomal sex. Lancet $2: 57-58$.

Nankin, H.R., and Louidice, T. 1974. Primary amenorthea in a 45,XX/46,XXq-female. Obstet. Gynecol. 44: 42-46.

Philip, J., Sele, V., and Trolle, D. 1965. Primary amenorrhea-A study of 101 cases. Feriil. Steril. 16: $795-804$.

Sarto, G.E. 1974. Cytogenetics of fifty patients with primary amenorrhea. Am. J. Obstet. Gynecol. 119: 14-23.

Shearman, R.P. 1968. Physiological approach to the differential diagnosis and treatment of primary amenorrhea. J. Obstet. Gynaec. Br. Commonw. 75: 1101-1107. 